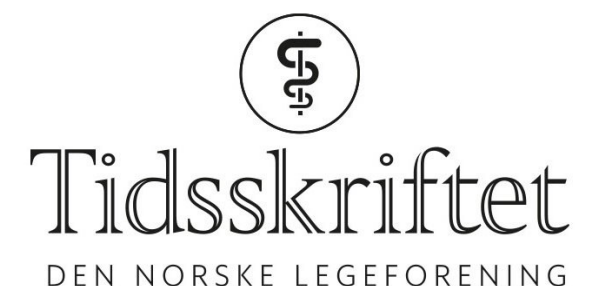

DEN NORSKE LEGEFORENING

\title{
Uventet effekt av sepsisbehandling i afrikansk studie
}

FRA ANDRE TIDSSKRIFTER

KRISTOFFER BRODWALL

Barne- og ungdomsklinikken Haukeland universitetssykehus

Offensiv behandling av lavt blodtrykk ved sepsis, som har vist god effekt i høyinntektsland, ga økt dødelighet i Zambia.

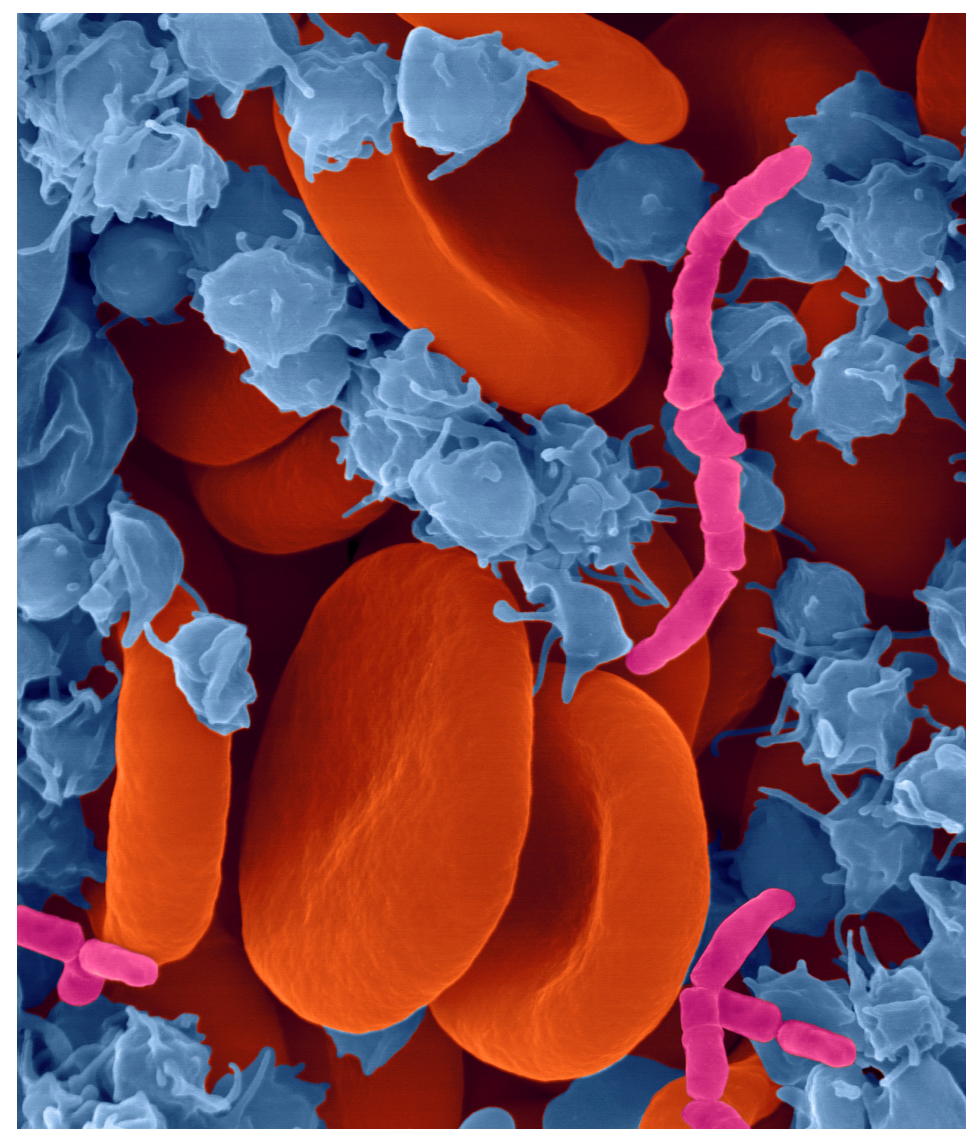

Illustrasjonsfoto: Science Photo Library

Dødeligheten ved sepsis har gått ned i mange land. Studier fra høyinntektsland tyder på at protokollbasert behandling av lavt blodtrykk ved sepsis har bidratt til dette. I lavinntektsog mellominntektsland, der dødeligheten ved sepsis fremdeles er høy, viser de få studiene som er gjort ikke samme entydig positive effekt. 
I en ny studie fra et universitetssykehus i Zambia ble 209 voksne pasienter (gjennomsnittsalder 37 år) med sepsis og lavt blodtrykk randomisert til enten offensiv behandling av hypotensjon etter protokoll eller til standardbehandling (1). $90 \%$ av pasientene var hivpositive, hvorav mange hadde lave $\mathrm{CD}_{4}$-verdier, og under halvparten av dem sto på antiretroviral behandling. Halvparten av pasientene hadde lungebetennelse. Tuberkulose ble mistenkt hos $63 \%$ og bekreftet med blodkultur hos $21 \%$.

Alle pasientene fikk relevant antiinfeksiøs behandling. Den protokollbaserte behandlingen besto i væsketilførsel med $2 \mathrm{l}$ de første to timene og nye $2 \mathrm{l}$ de neste fire timene, men med avbrudd ved tegn til økt sentralvenøst trykk. Hvis middelblodtrykket var under $65 \mathrm{~mm} \mathrm{Hg}$ etter de første $2 \mathrm{l}$ med væsketilførsel, fikk pasientene også behandling med vasopressor (dopamin). Blodoverføring ble gitt ved hemoglobinverdier under $7 \mathrm{~g} / 100 \mathrm{ml}$. Hos kontrollgruppen ble væske- og blodtrykksbehandlingen styrt etter behandlende leges skjønn. I gjennomsnitt fikk behandlingsgruppen nesten dobbelt så mye væske som kontrollgruppen.

Stikk i strid med forventningen var dødeligheten høyest hos dem som fikk protokollbasert behandling: $48 \%$ døde før utskrivning fra sykehuset, mot $33 \% \mathrm{i}$ kontrollgruppen (relativ risiko 1,46; $95 \% \mathrm{KI}$ 1,04-2,05). Forfatterne konkluderer med at flere studier er nødvendig for å forstå hvorfor intensivert behandling etter protokoll ikke hadde samme gode effekt ved sepsis og hypotensjon som den har i studier fra høyinntektsland.

\section{LITTERATUR:}

1. Andrews B, Semler MW, Muchemwa L et al. Effect of an Early Resuscitation Protocol on In-hospital Mortality Among Adults With Sepsis and Hypotension: A Randomized Clinical Trial. JAMA 2017; 318: 1233 - 40. [PubMed][CrossRef]

Publisert: 12. desember 2017. Tidsskr Nor Legeforen. DOI:10.4045/tidsskr.17.0949

(C) Tidsskrift for Den norske legeforening 2020. Lastet ned fra tidsskriftet.no 